\title{
Del debate electoral en TV al \\ ciberdebate en Twitter. Encuadres de influencia en las elecciones generales en España (28A)
}

\section{From TV debate to cyber debate on Twitter: frames of influence in the general elections in Spain (28A)}

\author{
Concha Pérez-Curiel; Mar García-Gordillo
}

Cómo citar este artículo:

Pérez-Curiel, Concha; García-Gordillo, Mar (2020). “Del debate electoral en TV al ciberdebate en Twitter. Encuadres de influencia en las elecciones generales en España (28A)". Profesional de la información, v. 29, n. 4, e290405.

https://doi.org/10.3145/epi.2020.jul.05

Artículo recibido el 30-04-2020

Aceptación definitiva: 02-06-2020

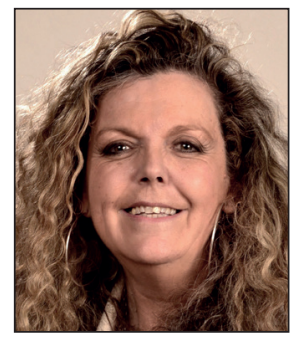

Concha Pérez-Curiel $\bowtie$

https://orcid.org/0000-0002-1888-0451

Universidad de Sevilla

Facultad de Comunicación

Departamento de Periodismo II

Avda. Américo Vespucio, s/n.

41092 Sevilla, España

cperez1@us.es

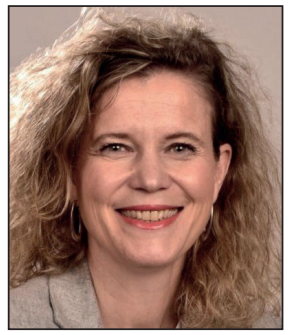

Mar García-Gordillo
https://orcid.org/0000-0002-9367-0366
Universidad de Sevilla
Facultad de Comunicación
Departamento de Periodismo II
Avda. Américo Vespucio, s/n.
41092 Sevilla, España
marggordillo@us.es

\section{Resumen}

El debate electoral televisado, lejos de perder protagonismo en favor de las redes sociales, se confirma como instrumento clave para la comunicación política. Las dos convocatorias previas a las elecciones generales del 28 de abril en España, retransmitidas con 24 horas de diferencia (RTVE y Atresmedia) suscitaron niveles de máxima expectación y priorizaron el conflicto como encuadre. Son objetivos de este estudio conocer los temas, estrategias y juegos discursivos del líder influencer y analizar las marcas retóricas del lenguaje político en Twitter. En los dos debates electorales (22 y 23 de abril de 2019) se aplicó una metodología de análisis de contenido cuantitativo, cualitativo y discursivo comparado, sobre una muestra general de mensajes en TV $(n 1=2.892)$ y una muestra específica de tweets publicados desde las cuentas de los partidos (n2 = 190). Se analizan los temas del debate (issue frame), las estrategias del candidato (game frame) y el nivel de influencia en Twitter a través de mecanismos de propaganda y falacia. Los resultados constatan que ambos debates responden a temas homogéneos, una respuesta activa de la audiencia y una tendencia basada en el discurso falso de la espectacularización.

\section{Palabras claves}

Comunicación política; Debates electorales; TV; Twitter; Líderes influencers; Partidos; Issue frame; Game frame; Conflicto; Falacia; Lenguaje de la espectacularización; Audiencia social.

\section{Abstract}

The televised electoral debate, far from losing prominence in favor of social media, is confirmed to be a key instrument for political communication. The two televised events prior to the general elections of 28 April in Spain, which were broadcast 24 hours apart (by RTVE and Atresmedia), raised great expectations and prioritized a conflictive atmosphere. The objectives of this study are to determine the issues, strategies, and discursive ploys of the leader-influencers and 
to analyze the rhetorical features of the political language on Twitter. In the context of these two electoral debates (22 and 23 April, 2019), a comparative quantitative, qualitative, and discursive content analysis methodology is applied to a general sample of messages on TV ( $\mathrm{n} 1=2,892)$ and a specific sample of tweets published on the accounts of the political parties ( $\mathrm{n} 2 \mathrm{=190}$ ). The issues debated (issue frame), the candidates' strategies (game frame), and the level of influence on Twitter are analyzed through propaganda and fallacy mechanisms. The results confirm that both debates covered homogeneous themes with an active response from the audience and a trend towards fake spectacularized discourse.

\section{Keywords}

Political communication; Electoral debates; TV; Twitter; Leader-influencers; Parties; Issue frame; Game frame; Conflict; Fallacy; Language of spectacularization; Social audience.

\section{Introducción}

La convivencia de pantallas off y online es marca de identidad de la comunicación política. La visibilidad del debate electoral televisado y la influencia de un discurso político espectacularizado y falso alcanzan cotas significativas de audiencia en las redes sociales. El debate como estrategia de candidatos y partidos ha sido objeto de estudio de investigaciones múltiples, inicialmente centradas en el campo de la televisión (Galindo-Arranz, 1998; Jamieson; Adasiewicz, 2000; Marín, 2003; Benoit; Hansen, 2004; Soengas, 2009; Padilla-Castillo, 2014) y con carácter más reciente, vinculadas a plataformas digitales (Wohn; Na, 2011; Lorente-Cano, 2011; Gallardo-Camacho; Lavín; Fernández-García, 2015; Ruiz-del-Olmo; Bustos-Díaz, 2016; Dader; Campos-Domínguez, 2017). Además, teorías sobre los efectos del debate en la decisión del voto (Yawn; Beatty, 2000; Benoit; Hansen; Verser, 2003), agenda mediática y pública (McCombs, 2005; Stromer-Galley, 2014; Mellado; Hellmueller; Donsbach, 2017), políticos influencers y fake news (López-Borrull; Vives-Gràcia; Badell, 2018; Sadiku; Eze; Musa, 2018) o relacionadas con el fact-checking (Graves; Cherubini, 2016; Wintersieck, 2017; Naderi; Hirst, 2018; Mazaira-Castro; Rúas-Araujo; Puentes-Rivera, 2019) conforman las distintas perspectivas desde las que se aborda el tema. Por otro lado, la irrupción de los nuevos soportes ha cambiado el proceso de cobertura de la política de forma significativa, lo que revierte en la creciente personalización, el progresivo negativismo, la tendencia a la cobertura cada vez más interpretativa y más basada en un esquema de juego (horse-race), a ver quién gana en el escenario electoral (García-Marín; Calatrava; Luengo, 2018; Reinemann; Wilke, 2007). A ello se suma un modelo de siscurso apoyado en la falacia y la propaganda del líder, como estrategia en la que valen más los sentimientos o emociones de la ciudadanía que la argumentación racional (Arrese, 2016; Boczkowski, 2016; Marzal-Felici; Casero-Ripollés, 2017; Urmeneta, 2017).

Aunque no superaron los rankings del debate de 2008 entre José Luis Rodríguez Zapatero y Mariano Rajoy (Barlovento, 2019c), con 13.043 .000 espectadores y un 59,1 por ciento de cuota de pantalla, la convocatoria electoral de 2019 alcanza cotas referentes de audiencia lineal, en especial los dos últimos debates en los que participaron los candidatos de las cuatro formaciones con mayor representación parlamentaria (PSOE, PP, Ciudadanos y Unidas Podemos) ${ }^{1}$. La primera cita (22 de abril) superó los 8,8 millones de espectadores (43,8\%) y la segunda (23 de abril) alcanzó más de 9,4 millones de audiencia (48,7\%). Desglosados los datos, se constata que la mayor parte del público siguió Antena 3 TV (5.283.000), La sexta (4.194.000) y TVE (7.245.000), según recogen los informes de Barlovento Comunicación (2019a; 2019b; 2019c)².

Los debates electorales televisados se enfrentan a un nuevo contexto compartido con las redes sociales y es necesario indagar en nuevas narrativas y procesos relacionados con la hibridación o el cambio hacia nuevos formatos. Además, la innovación en los modos de difusión del mensaje electoral, los efectos sobre la audiencia y la posibilidad que brindan de ensanchar el espacio público de la comunicación política (Rúas-Araujo; Quintas-Froufe, 2020) son focos de análisis empírico. Urge conocer el rol del candidato político, su capacidad de influir sobre la audiencia social con un discurso marcado por el conflicto y la táctica basada en la espectacularización de la palabra (Holtz-Bacha, 2003; Baym, 2010). Así mismo, en tiempos de postverdad, la desinformación y la falacia se instalan como marcas del lenguaje político en un entorno que convierte en viral la retórica de lo falso (Burkhardt, 2017; McNair, 2018). Se dibuja un escenario en el que las noticias falsas se difunden más lejos, más rápido y de forma más amplia que las verdaderas en todas las categorías de información (Vosoughi; Roy; Aral, 2018). Un marco de justificación del estudio que considera Twitter como una plataforma de amplificación del debate televisado $(\mathrm{H} 1)$ en un encuadre de conflicto diseñado por los líderes mediante usos de la retórica y el lenguaje de la espectacularización (H2).

\subsection{La revolución digital en el debate político. Cuestión de influencia}

La evolución de las campañas electorales pone de relieve el protagonismo de los debates en comunicación política. En las últimas cuatro décadas, su proliferación se ha consolidado como parte de una cada vez más visible tendencia de modernización, personalización (Berrocal-Gonzalo, 2003; Caprara, 2007; Campus, 2010; López-García et al., 2018.) y americanización o hibridación de las campañas (Anstead, 2016). En muchos países siguen siendo los eventos que generan una mayor audiencia y en algunos casos son los programas más seguidos de todo el año televisivo (Luengo, 2011; Freelon; Karpf, 2015). El actual proceso de convergencia e hibridación mediática mediante el uso de las segundas pan- 
tallas (Giglietto; Selva, 2014) o doble pantalla (Vaccari; Chadwick; O'Loughlin, 2015) se convierte para gobiernos y partidos en valor añadido de éxito, dada la potencialidad de las redes sociales para viralizar el mensaje. En concreto, Twitter se posiciona como red de microblogging favorita para el gremio político (López-Meri; Marcos-García; Casero-Ripollés, 2017), con capacidad para organizar campañas relativamente baratas, rápidas y con un público potencial muy amplio (Thelwall; Cugelman, 2017), difundir información electoral y declaraciones políticas (Campos-Domínguez, 2017) y movilizar el voto (Gainous; Wagner, 2014).

Desde sus orígenes (1960) con la retransmisión en la CBS del primer cara-cara entre John F. Kennedy y Richard Nixon (Carrera-Boleas, 2015), los debates televisados han estado vinculados a la figura del candidato, por delante de gobiernos y partidos e incluso, por delante de la ideología (Rahat; Sheafer, 2007). El primer debate televisivo con cuatro aspirantes a la presidencia del Gobierno en España (2015) señala un antes y un después en la producción y puesta en escena de estos eventos, en los que destaca un nuevo perfil de candidato, con un discurso más propio del marketing y del espectáculo que de la política. Se potencia la figura del influencer (Montoya; Vandehey, 2009; Pérez-Ortega, 2014; Rampersad, 2009), ligada a un uso intenso de Twitter (Jungherr, 2016) y a una eclosión de noticias falsas (Vosoughi; Roy; Aral, 2018; Rochlin, 2017).

La mentira política distribuida masivamente por Internet se ha convertido no sólo en una normalidad sino también en una nueva arma, muy potente, de propaganda (Journell, 2017). Si el funcionamiento de una democracia se sustenta en una opinión pública bien informada (Potter, 2006), si ésta es persuasivamente desinformada, aumentan exponencialmente las posibilidades de que las decisiones sociales sean poco eficientes y generen consecuencias adversas (Lewandowsky; Ecker; Cook, 2017). En este contexto, los debates electorales televisados ya actuaban como motores de información previamente seleccionada, a veces no filtrada y supeditada a un lenguaje con capacidad persuasiva, que potencia el liderazgo (Said-Hung; Prati; Cancino-Borbón, 2018). La televisión se contagia de Twitter (Miranda-Bustamante; Fernández-Medina, 2015) que se convierte no sólo en un canal de retorno para el espectáculo sino también en una parte del espectáculo en sí (Ruiz-del-Olmo; Bustos-Díaz, 2017).

En general, los políticos han normalizado el uso de Twitter y explotan cada vez más el potencial de la Twitter-retórica (López-Meri, 2016), como canal de interacción, sondeo y predicción en periodos electorales (Aragón et al., 2013; Sampedro-Blanco; Sánchez-Duarte; Poletti, 2013). Twitter se convierte en una cámara de eco de aquellos que dominan su uso (Verweij, 2012; Graham et al., 2013). Entre sus consecuencias más significativas en el tratamiento de la política cabe destacar el aumento del peso de la espectacularización (Reinemann; Wilke, 2007), la apuesta por nuevas narrativas y estéticas basadas en el protagonismo de las emociones (Beckett; Deuze, 2016) o el predominio del conflicto y los escándalos (Casero-Ripollés; Ortells-Badenes; Rosique-Cedillo, 2014). Ante tal combinación de factores, las audiencias responden a un ritmo automático de consumo, producción y viralización, que multiplica la posibilidad de influencia de un discurso político centrado en el líder.

\subsection{Contextualización del debate en el marco de las elecciones en España}

Las elecciones de 2015 supusieron un cambio radical en la forma de plantear los debates políticos. Por primera vez en la historia de la democracia de España se rompía mediáticamente el modelo bipartidista y se exhibían cuatro partidos con opciones de obtener una gran representación en el Congreso de los Diputados (Ruiz-del-Olmo; Bustos-Díaz, 2017).

Con este formato y en un clima marcado por el conflicto catalán, el avance de Vox y el pacto de la ultraderecha con el $P P$ y Ciudadanos en las elecciones andaluzas (Pérez-Curiel; García-Gordillo, 2019), se convocaron las primeras elecciones generales (28A), tras la moción de censura (2018) de Pedro Sánchez (PSOE) contra el entonces presidente Mariano Rajoy $(P P)$. A la importancia y expectación que alcanzaron los debates políticos televisados (García-Marín; Calatrava; Luengo, 2018) organizados de forma habitual desde el 2008, se sumó el protagonismo de las redes sociales y de la ciberpolítica, donde los públicos pueden ser parte activa del proceso (Aruguete, 2017; Wallsten, 2007; Meraz, 2011; Sung-Tae; Young-Hwan, 2007; López-López; Oñate, 2019) y el líder se convierte en macroestratega del lenguaje de la desinformación y la mentira (Wodak; Meyer, 2009).

Desde esta disyuntiva se plantean los siguientes objetivos:

O1. Analizar el rol del líder influencer en el debate y la proyección en Twitter de los temas (issue frame) y estrategias de juego político (game frame) desarrollados.

O2. Comprobar si existe una correspondencia en cuanto a la tematización en TV y Twitter y qué selección de contenidos se publica desde las cuentas del partido en esta red social.

O3. Relacionar las marcas retóricas del lenguaje y los mecanismos de propaganda y falacia con las estrategias de liderazgo político en Twitter.

En definitiva, se propone avanzar en líneas específicas que afectan al líder, a los electores y a las plataformas tradicionales y digitales en el contexto de los debates políticos. 


\section{Metodología}

Analizamos la cobertura del debate electoral en dos cadenas televisivas, en concreto, TVE y Atresmedia, en el marco de las elecciones del 28 de abril en España y la proyección de contenidos en una red como Twitter, con el fin de responder a las siguientes preguntas de investigación:

P.I.1. ¿Las redes sociales han supuesto un cambio en la selección de los temas y en el modo de tratarlos o son herederas del modelo tradicional del debate televisado?

PI.2. ¿Se convierte el líder, por delante de su partido, en el personaje protagonista de los mensajes publicados en Twitter mediante el uso de estrategias dirigidas a conseguir el voto electoral?

PI.3. ¿'Favorece Twitter la reproducción de tweets más relacionados con la confrontación, la espectacularización y la mentira?

Aplicamos una metodología de análisis de contenido cuantitativo, cualitativo (Silverman, 2016; Krippendorff, 2004; Neuendorf, 2002) y discursivo (Nocetti, 1990; Van-Dijk, 2015; Flowerdew; Richardson, 2017) basada en teorías aplicadas de issue frame/game frame (Aalberg; De-Vreese; Strömbäck, 2017; Cartwright; Stepanova; Xue, 2019).

Se diseña un estudio que parte de una observación coincidental de la oferta lineal (emisión en directo), social (publicaciones en RRSS) y de participación de la audiencia (live-tweeting). De los 23 debates previos, se seleccionan los dos más próximos a los comicios, emitidos en prime time por TVE (22:05) y Atresmedia (22:00) en los que participan los candidatos de los cuatro partidos con mayor representación parlamentaria: Pedro Sánchez (PSOE), Pablo Casado (PP), Albert Rivera (Ciudadanos) y Pablo Iglesias (Unidas Podemos). Del total de referencias de los políticos a los diferentes bloques definidos en el debate en TV (2.892) se analiza específicamente la marca de equivalencia temática, el tipo de estrategia y los registros retóricos del lenguaje en los tweets publicados (190), desde las cuentas digitales de cada partido durante el tiempo de emisión de los debates. En paralelo, se computan las métricas totales (365.928) y desglosadas (212.641 likes, 139.646 retweets y 13.641 comentarios), con el fin de conocer la participación de las audiencias durante ambas sesiones.

El rastreo de datos en TV se realiza mediante la visualización del debate en TVE y en Atresmedia, junto con el análisis del informe estadístico de Barlovento Comunicación, con datos de Kantar Media (abril 2019).

https://www.rtve.es/alacarta

https://www.atresplayer.com

Se utiliza la aplicación Twitonomy para rescatar las capturas de tweets. El programa elegido para el procesamiento de datos es el IBM SPSS Statistics, versión 24. La fiabilidad de los intercodificadores se ha calculado con la fórmula Pi de Scott, alcanzando un nivel de error de 0,98. La muestra responde a criterios e indicadores específicos:

- Se trata de los dos debates emitidos por la TV pública y privada más próximos a la cita electoral.

- Se selecciona a líderes y partidos (modelo bipartidista y emergente) con representación parlamentaria que consiguieron mayor número de votos durante las elecciones generales de 2016 (26J). Se descartan otros grupos políticos con menor número de escaños en el Congreso y el Senado. A ello se suma la decisión de la Junta Electoral Central (JEC) de desestimar la propuesta de Atresmedia para incluir a Vox en el debate, dado que en los comicios de 2015 sólo obtuvo el $0,1 \%$ de votos y no cuenta con representación en el Parlamento. La investigación se ciñe al formato de debate a cuatro aplicado finalmente en ambas cadenas

- Se elige Twitter dadas las ventajas que presenta para la comunicación política en campañas electorales (López-García, 2016; D’Heer; Verdegem, 2015) por delante de otras redes sociales como Facebook o Instagram.

- Se usan indicadores de cuantificación, cualificación y discursividad (tabla 1) junto con un programa estadístico, SPSS, que genere la contingencia, cruce y frecuencia de variables.

- Dado que el muestreo responde además al enfoque discursivo (Baker, 2006) se focaliza la atención en una cantidad específica de tweets (190), sobre los que se analizan las palabras clave que identifican mecanismos del lenguaje como la falacia y la propaganda.

Tabla 1. Indicadores métricos y variables de contingencia

\begin{tabular}{|c|c|c|c|c|}
\hline \multirow{2}{*}{ TV y Twitter } & Intervenciones de candidatos en TV & \multirow{2}{*}{$\begin{array}{l}\text { Temática } \\
\text { (issue frame) }\end{array}$} & \multirow{2}{*}{$\begin{array}{l}\text { Estrategias } \\
\text { (game frame) }\end{array}$} & \multirow{2}{*}{$\begin{array}{l}\text { Retórica del lenguaje } \\
\text { (falacia/propaganda) }\end{array}$} \\
\hline & $\begin{array}{l}\text { Tweets y variables de participación ciudadana } \\
\text { (likes, retweets y comentarios) }\end{array}$ & & & \\
\hline
\end{tabular}

La estructura metodológica responde a una triangulación de análisis de contenido comparado:

1. Análisis cuantitativo: incluye variables cuyo objetivo es la cuantificación simple, como la del número de referencias al tema y número de tweets o las subvariables de participación ciudadana (número de comentarios, retweets y favoritos), que se clasificarán como variables de escala. Así mismo, se cuantifica el índice de actividad en la cuenta de los partidos en Twitter durante las dos jornadas del debate a partir de la variable de frecuencia. 
2. Análisis cualitativo: integra las variables de temática general y temática específica desglosadas por issue frame

- Economía,

- Política social,

- Modelo territorial,

- Programa electoral,

- Populismo,

- Asuntos exteriores, y

- Corrupción)

y game frame

- Estrategia de gobierno y partidos

- Política de pactos,

- Personalización del candidato, y

- Medios de comunicación.

3. Análisis discursivo: refiere las variables relativas a recursos del lenguaje político a partir de una categorización de falacias y mecanismos de la propaganda

- apelación a la autoridad,

- apelación a la emoción,

- falacia contra el hombre,

- apelación a la fuerza,

- apelación a la ignorancia,

- atribuciones,

- causa falsa,

- énfasis,

- estereotipos,

- falsa analogía,

- hablar de otras fuentes,

- opiniones como hechos,

- selección de información,

- uso de etiquetas.

En línea con autores como Cleary, Horsfall y Hayter (2014) o Silverman (2016) se elige una muestra para el análisis en función de las palabras clave proporcionadas por el texto que se analiza.

En todos los casos, la estructura de bloques (tabla 2) se rige por criterios de selección de temas (issue frame) y tipo de estrategias (game frame) que definen el mensaje político.

Tabla 2. Categorías de análisis de los temas del debate en TV y equivalencia en Twitter

\begin{tabular}{|c|c|c|c|}
\hline & & & \\
\hline & Bloques temáticos & \multicolumn{2}{|r|}{ Codificación } \\
\hline \multirow{7}{*}{ Issue frame } & Economía & \multicolumn{2}{|c|}{$\begin{array}{l}\text { Empleo, paro, salarios, gasto público, deuda, crisis, impuestos, emprendimiento, contratos, } \\
\text { autónomos, política fiscal, inversión y presupuestos generales }\end{array}$} \\
\hline & Política social & \multicolumn{2}{|c|}{$\begin{array}{l}\text { Educación, sanidad, pensiones, estado del bienestar, justicia social, igualdad, violencia de } \\
\text { género, vivienda, inmigración y dependencia }\end{array}$} \\
\hline & $\begin{array}{l}\text { Modelo territorial del Estado (na- } \\
\text { cionalismo/independentismo) }\end{array}$ & \multicolumn{2}{|c|}{ Organización territorial del Estado, independentismo, nacionalismo, constitución y artículo 155} \\
\hline & Programa electoral & \multicolumn{2}{|c|}{ Temas recogidos en el programa y promesas electorales del candidato } \\
\hline & Populismo & \multicolumn{2}{|c|}{$\begin{array}{l}\text { Presencia de partidos populistas de izquierda y derecha en los parlamentos, Gobierno de } \\
\text { Venezuela y pactos con Vox }\end{array}$} \\
\hline & Asuntos exteriores & \multicolumn{2}{|l|}{ Unión Europea, Brexit y Gobierno Trump } \\
\hline & Corrupción & \multicolumn{2}{|c|}{ Críticas a gobiernos y partidos corruptos y medidas contra la corrupción política } \\
\hline \multirow{3}{*}{ Game frame } & Horse race and governing frame & $\begin{array}{l}\text { Estrategia de gobierno y partidos } \\
\text { y política de pactos }\end{array}$ & $\begin{array}{l}\text { Apoyos o críticas a la gestión del Gobierno } \\
\text { Críticas a la oposición } \\
\text { Política de pactos } \\
\text { Encuestas }\end{array}$ \\
\hline & Politicians as individuals frame & Personalización del candidato & $\begin{array}{l}\text { Referencia a su vida personal } \\
\text { Interacción con la audiencia } \\
\text { Participación y movilización } \\
\text { Espectacularización y show }\end{array}$ \\
\hline & News management frame & Medios de comunicación & $\begin{array}{l}\text { Información publicada en los medios } \\
\text { comparte información sobre la aparición de un } \\
\text { político en un medio de comunicación }\end{array}$ \\
\hline
\end{tabular}




\section{Análisis de resultados}

La explotación y discusión de resultados se divide en tres fases, cada una de las cuales se relaciona con los tipos de variables que codifica SPSS.

Fase 1. Variables numéricas. Aplicadas a la cuantificación simple de tweets y al grado de participación ciudadana.

En esta primera fase se contabiliza el número de mensajes publicados desde las cuentas de cada partido así como el total de likes, retweets y comentarios que los seguidores han difundido en Twitter en cada debate. Se diseña una tabla con variables numéricas o de escala.

Tabla 3. Comparativa de métricas de partidos en Twitter y desglose por debate

\begin{tabular}{|c|c|c|c|c|c|c|}
\hline \multicolumn{7}{|c|}{ Resumen de casos. Métricas del debate en TVE } \\
\hline & & $\begin{array}{l}\text { Número de } \\
\text { tweets }\end{array}$ & $\begin{array}{c}\text { Número de me } \\
\text { gusta }\end{array}$ & $\begin{array}{l}\text { Número de } \\
\text { retweets }\end{array}$ & $\begin{array}{l}\text { Número de } \\
\text { comentarios }\end{array}$ & $\begin{array}{c}\text { Cuantificación } \\
\text { por partidos }\end{array}$ \\
\hline \multicolumn{2}{|l|}{ @PSOE } & 10 & 16.463 & 12.313 & 1.167 & 29.943 \\
\hline \multicolumn{2}{|l|}{$@ P P$} & 17 & 12.871 & 9.629 & 1.180 & 23.680 \\
\hline \multicolumn{2}{|l|}{ @Ciudadanos } & 22 & 25.063 & 17.535 & 2.762 & 45.360 \\
\hline \multicolumn{2}{|l|}{ @Podemos } & 20 & 23.188 & 14.754 & 720 & 38.662 \\
\hline \multirow{5}{*}{ Total } & Media & 17,25 & $19.396,25$ & $13.557,75$ & $1.457,25$ & $34.411,25$ \\
\hline & Mediana & 18,50 & $19.825,50$ & $13.533,50$ & $1.173,50$ & $34.302,50$ \\
\hline & Suma & 69 & 77.585 & 54.231 & 5.829 & 137.645 \\
\hline & Mínimo & 10 & 12.871 & 9.629 & 720 & 23.680 \\
\hline & Máximo & 22 & 25.063 & 17.535 & 2.762 & 45.360 \\
\hline \multicolumn{7}{|c|}{ Resumen de casos. Métricas del debate en Atresmedia } \\
\hline & & $\begin{array}{l}\text { Número de } \\
\text { tweets }\end{array}$ & $\begin{array}{c}\text { Número de me } \\
\text { gusta }\end{array}$ & $\begin{array}{l}\text { Número de } \\
\text { retweets }\end{array}$ & $\begin{array}{l}\text { Número de } \\
\text { comentarios }\end{array}$ & $\begin{array}{c}\text { Cuantificación } \\
\text { por partidos }\end{array}$ \\
\hline \multicolumn{2}{|l|}{ @ PSOE } & 39 & 26.956 & 20.218 & 2.643 & 49817 \\
\hline \multicolumn{2}{|l|}{$@ P P$} & 27 & 17.900 & 13.803 & 1.732 & 33435 \\
\hline \multicolumn{2}{|l|}{ @Ciudadanos } & 30 & 18.138 & 14.232 & 1.401 & 33771 \\
\hline \multicolumn{2}{|l|}{$@$ @odemos } & 25 & 72.062 & 37.162 & 2.036 & 111260 \\
\hline \multirow{5}{*}{ Total } & Media & 30,25 & $33.764,00$ & $21.353,75$ & $1.953,00$ & $57.070,75$ \\
\hline & Mediana & 28,50 & $22.547,00$ & $17.225,00$ & $1.884,00$ & $41.794,00$ \\
\hline & Suma & 121 & 135.056 & 85.415 & 7.812 & 228.283 \\
\hline & Mínimo & 25 & 17.900 & 13.803 & 1.401 & 33.435 \\
\hline & Máximo & 39 & 72.062 & 37.162 & 2.643 & 111.260 \\
\hline Totales Globales & & 190 & 212.641 & 139.646 & 13.641 & 365.928 \\
\hline
\end{tabular}

Los datos en negrita corresponden al total del cómputo de tweets y métricas desglosado por debates

Como muestran los resultados (tabla 3), el último de los debates televisados alcanzó en Twitter una actividad política y ciudadana superior, siguiendo la tónica general del incremento de interés público en los debates más cercanos a las elecciones. Todos los partidos aumentan el número de tweets y destaca el PSOE (39) frente a la primera sesión (10). En cuanto a los datos de participación, es relevante señalar las diferencias en las métricas alcanzadas por Ciudadanos entre el primer debate (45.360) y el segundo (33.771), superado por PSOE (49.817) y sobre todo por UP (111.260), con un gran incremento respecto a la primera convocatoria.

Por delante de likes y retweets, los comentarios del público aportan códigos de significado textual, a través de los cuáles los líderes pueden conocer la opinión, la propuesta o la crítica de la audiencia. En este sentido, Ciudadanos es el partido que mayor número de comentarios alcanza en la primera emisión (2.762) mientras que en el segundo debate consigue los resultados más bajos (1.401). En contraposición, el partido de Pablo Iglesias muestra diferencias notables entre ambas convocatorias (720/2.036) y además se posiciona como el grupo político que alcanza cotas máximas de respuesta usuaria (149.922).

El papel de las audiencias y su función como echo-chambers y amplificadoras del discurso concentra la atención de los líderes, aunque como avanzan investigaciones previas (Cha et al., 2010) una respuesta masiva de seguidores en Twitter no garantiza el aumento de votos ni el triunfo electoral. Se trata de procesos en los que por delante del número de seguidores, es preciso analizar códigos temáticos y retórica discursiva relacionada con la influencia.

El debate electoral en Twitter tiende a un incremento de la interpretación, la espectacularización y el conflicto como esquemas de juego político (horse-race) 
Fase 2. Variables categóricas. Aplicadas al análisis cualitativo temático, de indicadores con una respuesta de entre más de dos respuestas posibles.

Desde la base de datos se categorizan:

- la variable 'Debate', de carácter nominal dicotómica, donde sus dos únicos posibles valores son Debate en TVE o Debate en Atresmedia;

- la variable 'Medio', con posibles valores TV o Twitter; y

- una variable de tipo escala numérica por cada uno de los temas, marcando como etiquetas de valor 'Issue frame' y 'Game frame'.

Tabla 4. Contingencia de valores por temática y estrategia en TV y Twitter (\%)

\begin{tabular}{|c|c|c|c|c|c|c|c|c|c|}
\hline & Temas & $\begin{array}{l}\text { N. per- } \\
\text { didos }\end{array}$ & $\begin{array}{c}\text { Media } \\
\text { TVE/ Twitter }\end{array}$ & $\begin{array}{c}\text { Media } \\
\text { Atresmedial } \\
\text { Twitter }\end{array}$ & $\begin{array}{l}\text { Media } \\
\text { global }\end{array}$ & Mediana & $\begin{array}{c}\text { Desviación } \\
\text { estándar }\end{array}$ & Min & Max \\
\hline \multirow{8}{*}{$\begin{array}{l}\text { Issue frame } \\
\text { (temas) }\end{array}$} & Economía & 0 & 20,1 & 19,0 & 19,5 & 19,2 & 6,2 & 12,0 & 32,0 \\
\hline & Política social & 0 & 18,2 & 15,9 & 17,1 & 17,1 & 6,2 & 5,5 & 28,2 \\
\hline & Programa electoral & 0 & 10,6 & 7,6 & 9,1 & 8,1 & 3,8 & 3,7 & 16,0 \\
\hline & Modelo territorial & 0 & 15,6 & 16,3 & 15,9 & 16,2 & 6,8 & 4,0 & 27,4 \\
\hline & Populismo & 0 & 1,3 & 2,0 & 1,6 & 0,0 & 2,6 & 0,0 & 8,0 \\
\hline & Asuntos exteriores & 0 & 0,1 & 0,1 & 0,1 & 0,0 & 0,2 & 0,0 & 0,9 \\
\hline & Corrupción & 0 & 5,3 & 6,3 & 5,8 & 5,3 & 3,1 & 0,9 & 11,1 \\
\hline & & & & & 69,4 & & & & \\
\hline \multirow{5}{*}{$\begin{array}{l}\text { Game frame } \\
\text { (estrategias) }\end{array}$} & Gobierno y partidos & 0 & 18,2 & 17,8 & 18,0 & 17,0 & 5,5 & 10,1 & 30,6 \\
\hline & Pactos & 0 & 7,3 & 9,7 & 8,5 & 8,1 & 5,2 & 0,0 & 17,8 \\
\hline & Personalización & 0 & 1,3 & 2,8 & 2,0 & 1,1 & 2,5 & 0,0 & 8,0 \\
\hline & Medios de comunicación & 0 & 1,7 & 1,9 & 1,8 & 0,4 & 2,3 & 0,0 & 6,8 \\
\hline & & & & & 30,5 & & & & \\
\hline
\end{tabular}

Los porcentajes en negrita indican los temas y estrategias principales en TV y Twitter. La media global dividida por issue frame y game frame se señala en rojo.

Si nos regimos por la categorización operativa de issue frame y game frame (tabla 4), sobresalen Economía $(19,5)$ y Política social $(17,1)$ como bloques más tratados y Gobiernos y partidos $(18,0)$ junto con Política de pactos $(8,5)$, correspondientes a estrategias (horse and governing frame). Igualmente, el bloque de Modelo territorial $(15,9)$ aparece como marca de conflicto y enfrentamiento entre candidatos, en un contexto definido por los antecedentes del Proceso soberanista en Cataluña. Sin representar valores destacados, la corrupción se sitúa como parte del discurso en ambos encuentros $(5,8)$ alcanzando la cota más elevada en el debate de Atresmedia $(6,3)$. Se trata de una herramienta de acusación entre partidos, relacionada con estrategias de game frame como la espectacularización que, algunos líderes como Albert Rivera (CS) convierten en objetivo del debate y de su programa electoral. Los casos ERE, Acuamed, o Narbona contra el $P S O E$ o Gürtel, Bárcenas y Cifuentes, en los que se vio implicado el $P P$, son líneas de conflicto y de acusación directa o indirecta hacia el bipartidismo de los partidos emergentes (UP destaca el caso Villarejo, "las cloacas del Estado" y "las puertas giratorias").

Los porcentajes indican además una relevancia de los temas de issue frame $(69,4)$ por delante de las estrategias de game frame $(30,5)$, aunque se describe un proceso complementario entre agenda y estrategias políticas (tabla 4). Una constante en ambos debates es la confrontación y el ataque verbal relacionado con la gestión del Gobierno y los pactos políticos (horse race and governing frame), un modus operandi focalizado en el conflicto (politicians as individuals frame) y de relación con los medios de comunica-

La propaganda y la falacia se reproducen como marcas del discurso político en el entorno viral de Twitter

\section{ción (news management frame), ambas con porcentajes}

mínimos (2,0/1,8), en las que destaca Albert Rivera, que enfatiza el discurso con documentos (fotos, informes, libros, noticias) y Pablo Iglesias respondiendo a los medios sobre "la compra del chalé" que provocó la polémica ante la opinión pública.

El protagonismo de los líderes en Twitter es un reflejo del rol que desempeñan en el debate televisado. Los tweets publicados desde las cuentas de los partidos resaltan la imagen del líder y la relevancia del tema. 


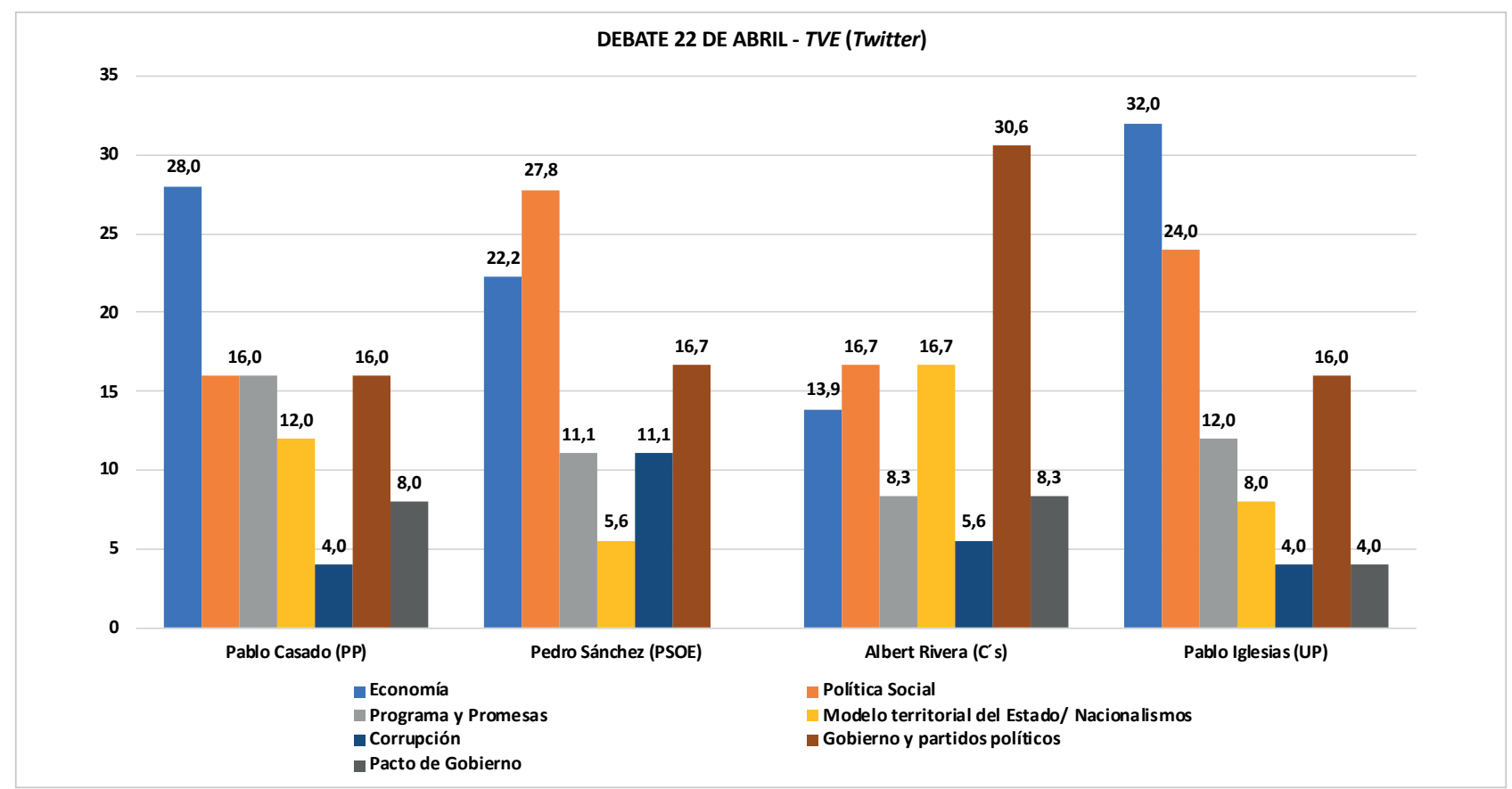

Gráfica 1. Comparativa y cruce por bloque temático y liderazgo en Twitter (debate 1)

En el debate retransmitido por TVE (gráfica 1) los datos ponen de relieve qué temas protagonizan el discurso de los candidatos en Twitter. El bloque de Economía concentra especialmente el interés de Pablo Iglesias $(32,0)$ y Pablo Casado $(28,0)$, con posiciones divergentes en sus análisis. El dirigente popular recurre en los tweets a la crítica de la gestión del gobierno actual frente a la de otros gobiernos del $P P$, a la falta de empleo y a la política fiscal mientras que el líder de Unidas Podemos centra su atención en la subida de impuestos o la reforma laboral. Por su parte, la seña de identidad temática de Pedro Sánchez es la Política social $(27,8)$, un bloque referente en el programa del partido y en las políticas gubernamentales desarrolladas en su etapa como presidente. Justicia social, pensiones o igualdad, sin descartar otros frentes como educación, violencia de género y un mensaje crítico dirigido a Ciudadanos $(16,7)$ y al $P P(16,0)$ por la falta de consenso parlamentario, fueron temas estrella del candidato socialista en Twitter. Sólo Pablo Iglesias $(24,0)$ se aproxima a las cotas de Pedro Sánchez, con tweets sobre sanidad, pensiones y desigualdad como ejes centrales de su discurso. Es destacable la posición de Albert Rivera $(16,7)$ sobre el modelo territorial y los nacionalismos, que marcan la campaña del partido ante el conflicto catalán con incoaciones referidas al independentismo, los políticos presos o la aplicación del artículo 155 de la Constitución española.

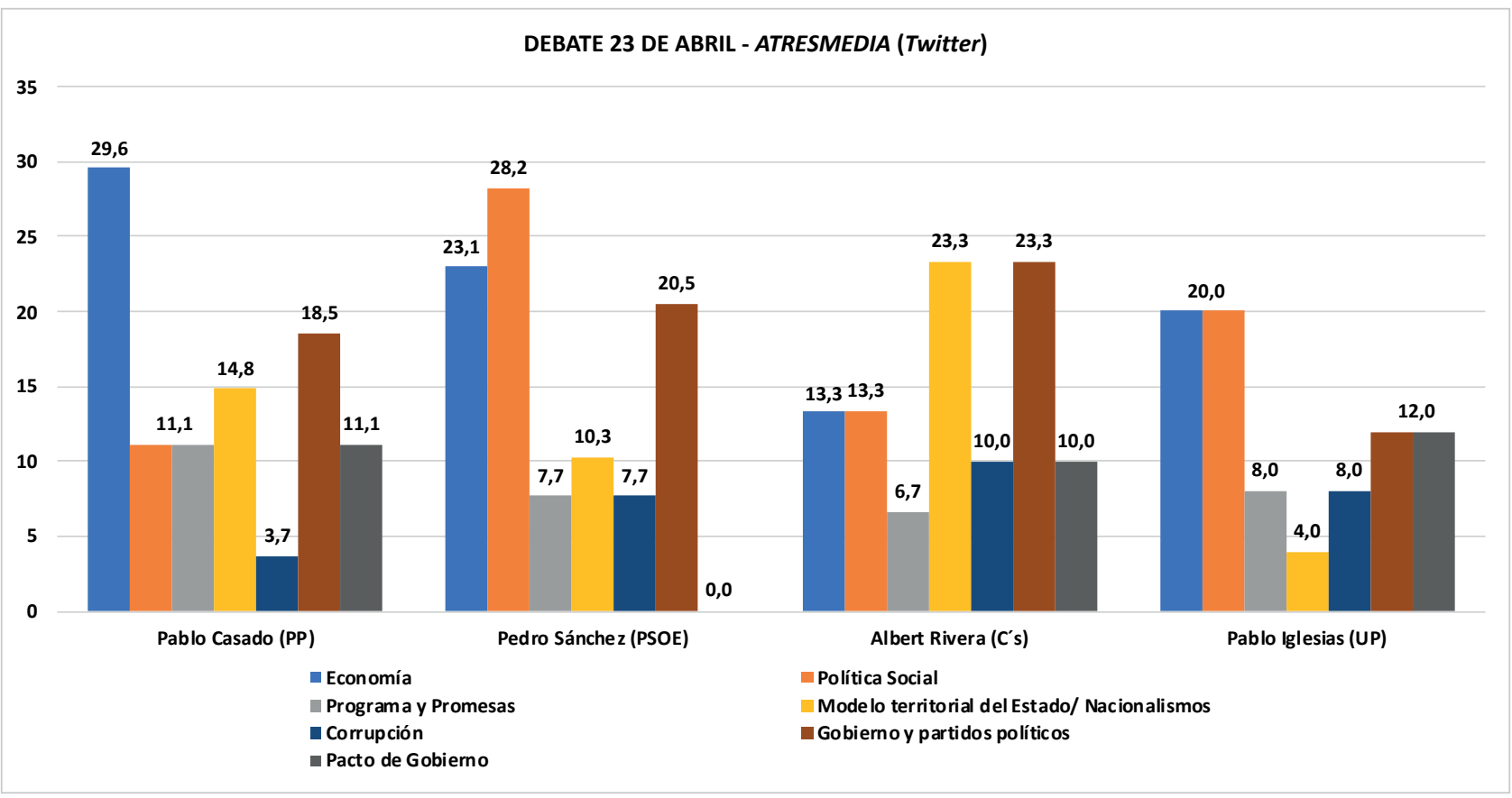

Gráfica 2. Comparativa y cruce por bloque temático y liderazgo en Twitter (debate 2) 
Una marca estratégica común del discurso es promover la confrontación entre los partidos y las críticas hacia el Gobierno, aunque se manifiesta como una constante de los mensajes de Albert Rivera $(30,6)$, que supera con creces al resto de candidatos. Es reseñable la falta de respuesta de Pedro Sánchez ante la política de pactos, un bloque reiterativo de Ciudadanos $(8,3)$ y el $P P(8,0)$ ante el previsible acuerdo postelectoral entre PSOE y Unidas Podemos.

La posición de los líderes en la cita de Atresmedia mantiene coordenadas del primer debate. Se incrementan propuestas de contenidos, se enfatizan los temas-fuerza y se acrecienta la batalla dialéctica sobre los pactos postelectorales.

De nuevo, Economía y Política social son bloques que identifican a los líderes del bipartidismo (gráfica 2). Pablo Casado $(29,6)$ y Pedro Sánchez $(28,2)$ refuerzan la oferta programática electoral, seguido por Pablo Iglesias $(20,0)$ con mensajes que abogan por el bienestar de la clase trabajadora. Se desmarca de este denominador común Albert Rivera, que repite moldes respecto al día anterior, centrando la máxima atención en las críticas sobre futuros pactos con los nacionalistas catalanes $(23,3)$. El indicador de conflicto entre Gobierno y partidos alcanza también en esta ocasión cotas elevadas entre los candidatos, con estrategias destacadas de Albert Rivera $(23,3)$ y Pablo Casado $(18,5)$ que recurren a informes económicos, recortes de prensa, imágenes, libros, plagios de tesis y fotos comprometidas o al supuesto apoyo de UP a los partidos pro-independencia.

Asuntos como el programa y las promesas electorales o la corrupción política no se han considerado núcleo de atención de los tweets publicados, aunque Pedro Sánchez $(11,1)$, sobre todo en el primer debate, utiliza los casos de corrupción del $P P$, como estrategia de ataque contra el adversario.

\section{Fase 3. Variables de respuesta múltiple. Aplicadas al análisis discursivo y de retórica del lenguaje}

Para completar la triangulación del método, se realiza un estudio de cada uno de los tweets publicados desde las cuentas del partido, codificando los diferentes recursos y mecanismos del lenguaje político que favorecen la desinformación y pueden tener efectos en el grado de influencia del líder sobre los seguidores del debate. Se diseña en SPSS una tabla cruzada con variables categóricas que combina figuras de la propaganda y la falacia con los líderes de cada grupo político.

Tabla 5. Contingencia y mecanismos del lenguaje en Twitter (\%)

\begin{tabular}{|c|c|c|c|c|c|c|}
\hline \multicolumn{2}{|c|}{ Categorías } & $\begin{array}{c}\text { @PSOE } \\
\text { Pedro Sánchez }\end{array}$ & $\begin{array}{c}\text { @Populares } \\
\text { Pablo Casado }\end{array}$ & $\begin{array}{c}\text { @CiudadanosCs } \\
\text { Albert Rivera }\end{array}$ & $\begin{array}{c}\text { @Podemos } \\
\text { Pablo Iglesias }\end{array}$ & Valores medios \\
\hline Apelación a la autoridad & \multirow{14}{*}{$\begin{array}{l}\text { \% dentro de } \\
\text { Recursos }\end{array}$} & 13,2 & 11,3 & 11,5 & 12,3 & 12,1 \\
\hline Apelación a la emoción & & 10,4 & 11,6 & 13,2 & 14,5 & 12,4 \\
\hline Falacia contra el hombre & & 3,6 & 0,0 & 0,2 & 2,2 & 1,5 \\
\hline Apelación a la fuerza & & 7,5 & 7,1 & 6,3 & 7,1 & 7,0 \\
\hline Apelación a la ignorancia & & 13,3 & 14,2 & 12,1 & 13,2 & 13,2 \\
\hline Atribuciones & & 9,3 & 9,1 & 9,1 & 8,3 & 8,9 \\
\hline Causa falsa & & 0.0 & 2,3 & 0,0 & 0,6 & 0,7 \\
\hline Énfasis & & 4,2 & 4,2 & 6,1 & 5,1 & 4,9 \\
\hline Estereotipos & & 2,6 & 0,0 & 3,2 & 0,0 & 1,4 \\
\hline Falsa analogía & & 0,0 & 1,2 & 3,2 & 0,0 & 1,1 \\
\hline Hablar de otras fuentes & & 7,7 & 9,1 & 7,1 & 7,2 & 7,7 \\
\hline Opiniones como hechos & & 7,6 & 8,9 & 9,2 & 9,2 & 8,7 \\
\hline Selección de información & & 10,3 & 10,9 & 10,1 & 9,1 & 10,1 \\
\hline Uso de etiquetas & & 9,2 & 9,8 & 8,6 & 9,1 & 9,1 \\
\hline
\end{tabular}

Los porcentajes en negrita señalan los tipos de recursos más utilizados por los líderes políticos. En un mismo tweet puede aparecer más de uno.

Los valores medios en todos los casos analizados (tabla 5) se concentran en las figuras:

- apelación a la ignorancia $(13,2)$,

- apelación a la emoción $(12,4)$,

- apelación a la autoridad $(12,1)$,

- selección de la información $(10,1)$,

- uso de etiquetas $(9,1)$,

- atribuciones (8,9), y

- opiniones como hechos $(8,7)$.

Estos registros ponen de relieve un tipo de discurso basado en la confrontación entre líderes y la crítica al Gobierno y a los partidos (apelación a la autoridad, atribuciones y uso de etiquetas) pero fundamentalmente en un mensaje falso dirigido a las audiencias (apelación a la ignorancia y apelación a la emoción). 
Si se centra la atención en el caso concreto de cada líder, destaca el comportamiento de los candidatos de partidos emergentes como Pablo Iglesias $(14,5)$ y Albert Rivera $(13,2)$, en cuanto al uso de la apelación a la emoción. Esta dinámica se completa en los debates televisados y más tarde en las redes sociales con escenificación, uso de la comunicación no verbal (kinésica) y otras estrategias de espectacularización.

Frente a ellos, los líderes del bipartidismo político tradicional alcanzan máximas en la producción de tweets que apelan a la ignorancia del receptor, estrategia en la que Pablo Casado $(14,2)$ y Pedro Sánchez $(13,3)$ superan al resto de candidatos. Se suman otras como la selección de la información $(10,9 / 10,3)$ con la eliminación interesada de datos de interés público o uso de etiquetas $(9,8 / 9,2)$ y apelativos directos que critican o alaban a la fuente. Vinculado a la figura de Pedro Sánchez como presidente del Gobierno, destacan los tweets en los que se ve reflejada la apelación a la autoridad de la institución $(13,2)$ sobre la que recae el ataque político del resto de líderes, especialmente de Pablo Iglesias $(12,3)$.

Una característica intrínseca a las estrategias del juego político (game frame) reside en el uso de atribuciones, que abundan en los éxitos y errores de aliados y contrincantes, un aspecto en el que todos los partidos consiguen cotas relevantes.

\section{Otras figuras como}

- apelación a la fuerza $(7,0)$,

- hablar de otras fuentes $(7,7)$,

- énfasis $(4,9)$,

- falacia contra el hombre $(1,5)$,

- estereotipos $(1,4)$,

- falsa analogía $(1,1)$ o

- causa falsa $(0,7)$,

como valor de media, contribuyen a potenciar un tipo de discurso marcado por la crítica a la actuación del contrario, la política de pactos y el protagonismo del líder ante las audiencias.

La selección de tweets publicados muestra la localización de figuras del lenguaje y la espectacularización en el texto y cómo se han tratado por parte de los líderes. Pablo Casado, líder del $P P$, recurre a la creación de empleo (imagen 1) y resalta la gestión económica del PP mientras estuvo en el Gobierno. Usa falacias de apelación a la fuerza

"para llevar a cabo la mayor revolución fiscal de la historia".

Es frecuente el uso de opiniones como hechos (se anuncia la creación de dos millones de puestos de trabajo), promoviendo además la apelación a la ignorancia de la ciudadanía.

Por su parte, Pedro Sánchez, candidato del PSOE (imagen 2) incorpora la apelación a la fuerza de todos los españoles, utilizando el término "moción de censura", acción que le permitió desbancar a Mariano Rajoy (PP) de la Presidencia del Gobierno. Así mismo, mediante la apelación a la autoridad, aboga por la lucha contra la corrupción, un asunto que también provoca la crítica, especialmente de los partidos emergentes (Cs y $U P$ ) contra los múltiples casos asociados a los partidos tradicionales ( $P S O E$ y $P P$ ). Utiliza el énfasis en un tema como la lucha contra la desigualdad, un identificador en el programa de las políticas socialistas.

\section{El actual proceso de convergencia de las multipantallas potencia los niveles de in- fluencia del líder}

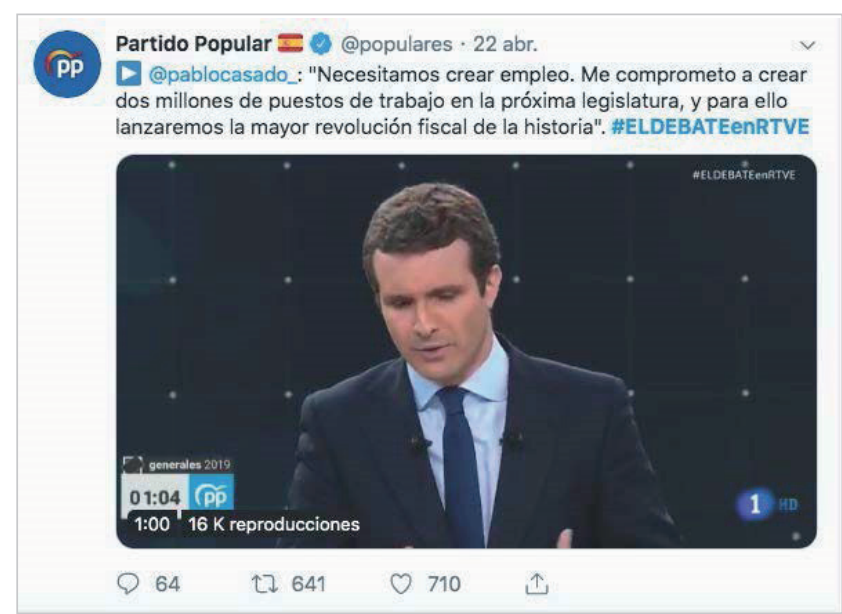

Imagen 1. Apelación a la fuerza, Opiniones como hechos, Apelación a la ignorancia.

https://twitter.com/populares/status/1120422691851337728?s=20

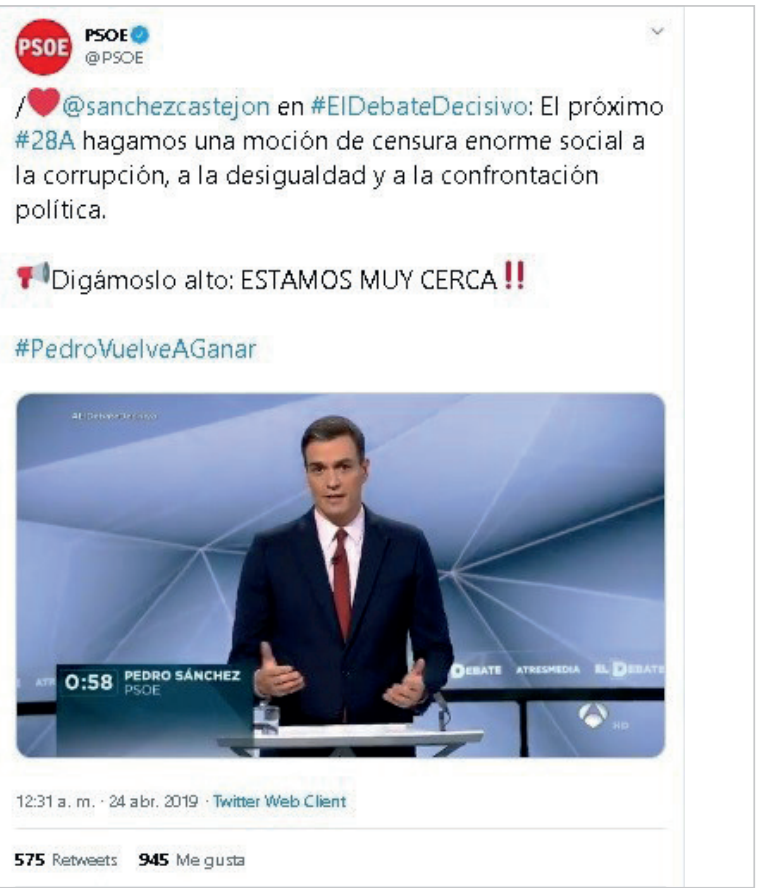

Imagen 2. Apelación a la fuerza, Apelación a la autoridad, Énfasis. https://twitter.com/PSOE/status/1120817386435821572?s=20 
El líder de UP, Pablo Iglesias (imagen 3), se caracteriza por un discurso de apelación a la emoción, una estrategia que utiliza desde el primer momento y que agudiza en el minuto final dirigido a pedir el voto a los electores. El candidato recurre a la falsa analogía, falacia que relaciona los impuestos sólo con la clase trabajadora y no con otros estratos de población. El uso de etiquetas es también un denominador común de sus tweets, recurriendo a términos como "minorías", "privilegiados" o "gente trabajadora", códigos de su programa político.

Por último, el líder de Cs, Albert Rivera (imagen 4), alcanza cotas máximas de escenificación que incluye humor e ironía para interpelar a todos los candidatos y en particular, al presidente del Gobierno con respecto a su intención de pacto con UP o con los partidos independentistas. Los tweets encierran marcas discursivas como el uso de etiquetas ("carca" para referirse a Pedro Sánchez), hablar de otras fuentes (la situación de las mujeres o los nacionalistas) o la selección de la información (se sobredimensiona el conflicto frente a otros acontecimientos)

Es destacable la cantidad y variedad de recursos que los líderes integran en sus tweets. Con menor porcentaje aparecen otras falacias, como la causa falsa cuando Albert Rivera afirma:

"Torra es un totalitario xenófobo y por eso necesitamos un gobierno constitucionalista, sin separatistas".

https://bit.ly/2UUTvSv

las atribuciones, como las que Pedro Sánchez, anuncia en su tweet:

“¿Qué estamos haciendo? -Se están creando 1.483 empleos diariamente -Plan de lucha contra el paro de larga duración -Plan de lucha por el empleo juvenil".

https://twitter.com/PSOE/status/1120423857721151488?s=20

o los estereotipos, como los utilizados por Pablo Casado:

"Es inadmisible que por primera vez en la historia de España pacte con los proetarras de Bildu".

https://twitter.com/populares/status/1120434469700341760?s=20

\section{Conclusiones}

La nueva narrativa del debate electoral en las redes sociales invita a la reflexión sobre la novedad, la permanencia o los cambios respecto al formato tradicional del debate televisado.

A partir de teorías centradas en los efectos del debate político en la TV (Soengas, 2009; Padilla-Castillo, 2014), en las campañas políticas en Twitter (Enli, 2017) y en la influencia sobre la decisión del voto (Yawn; Beatty, 2000; Benoit; Hansen; Verser, 2003), la investigación revela una equivalencia temática, una táctica política común y un discurso basado en la confrontación y la espectacularización del lenguaje. Destacan valores añadidos de las redes sociales como la capacidad de instantaneidad y viralización del mensaje (Dader; Campos-Domínguez, 2017), sumado a una tendencia basada en un esquema de juego (horse-race) en el escenario electoral (García-Marín; Calatrava; Luengo, 2018).

En consonancia con estudios previos sobre influencia política (Pérez-Curiel; Limón-Naharro, 2019), el líder, por delante de gobiernos y partidos, se postula como centro de interés del debate en televisión y Twitter. Así mismo y tomando como base los principios teóricos de issue frame y game frame (Aalberg; De-Vreese; Strömback, 2017; Cartwright; Stepanova; Xue, 2019), se relacionan ambos encuadres, los contenidos del programa electoral y los juegos estratégicos del candidato, para comprobar, por un lado, a qué tipo de temas se ha dedicado más espacio y tiempo en la cobertura del debate y por otro, analizar qué meca-
Los debates en TV ya actuaban como motor de información no filtrada y supeditada al lenguaje persuasivo 
nismos de horse race and governing frame (estrategias de Gobierno y partidos, Política de pactos y Personalización) o news management frame (relacionados con Medios de comunicación) se localizan en el desarrollo del debate.
Los políticos han normalizado el uso de Twitter y explotan cada vez más el potencial de la Twitter-retórica

Los resultados ponen de manifiesto la coincidencia entre los issue frame más tratados (Economía y Política social) y los game frame más usados (Confrontación de gobiernos y partidos y Política de pactos) en televisión y Twitter. Sobresalen además otros bloques temáticos como Modelo territorial, dado el protagonismo de la situación de Cataluña y los pactos con los grupos independentistas o el bloque destinado a Corrupción política, presente en el discurso de todos los líderes, pero especialmente, un bastión de crítica de los nuevos partidos. En definitiva, las nuevas narrativas de los medios sociales no han supuesto cambios significativos en cuanto a la selección de bloques temáticos ni en cuanto al procedimiento de confrontación y ataque al adversario. El valor añadido de la red social es la capacidad de llegar a más público, la instantaneidad y la interacción, no siempre compartida por los líderes (Fuchs, 2014; Vosoughi; Aral, 2018).

La propuesta investigadora indaga en los estudios sobre el análisis crítico del discurso (Van-Dijk, 2015; Flowerdew; Richardson, 2017). Como aportación de la investigación a las teorías relacionadas, se confirma un uso retórico del lenguaje político en los mensajes del líder, convertidos en herramientas básicas del proceso de selección, producción y difusión de los contenidos. En este escenario, el poder de amplificación a modo de eco-chamber de una red como Twitter (Rúas-Araujo; Quintas-Froufe, 2020) puede multiplicar los efectos del discurso falaz que define la actitud de los líderes y su previsible objetivo electoral ante una audiencia social con índices referentes de participación activa. En el plano discursivo destaca el protagonismo de la falacia y de figuras propias de la propaganda. La apelación a la emoción, con porcentajes significativos en el caso de los partidos emergentes, frente a la apelación a la autoridad más localizada en los mensajes de los partidos bipartidistas, confluyen en un denominador común como es el uso de la apelación a la ignorancia en el que destacan los cuatro candidatos. Mecanismos como la selección de la información (el líder sólo revela una parte del todo), las atribuciones (centradas en logros políticos no siempre demostrados), el uso de la fuerza (llamando a la revolución de las partes afines), las opiniones como hechos (con convencimiento de hacerlas realidad), la causa falsa (no existe relación con la consecuencia) o los estereotipos (se recurre a la calificación negativa de la fuente para provocar el conflicto) describen el uso estratégico del lenguaje como seña de identidad de la comunicación política (Wodak; Meyer, 2009). Twitter no es ajeno a esta ceremonia de la confusión (Rodríguez-Ferrándiz, 2019).

La eclosión de las redes sociales no ha cambiado la intencionalidad del discurso electoral; si cabe, la ha multiplicado. La proliferación de estudios sobre la posverdad, la desinformación y los bulos (fake news) muestra un consenso común ante el uso de la mentira, como arma de propaganda política (Journell, 2017; Allcott; Gentzkow, 2017). En esta línea hay que considerar los procesos desarrollados por plataformas de fact ckecking como Newtral, con verificaciones en directo de las declaraciones de los candidatos en ambos debates ${ }^{3}$.

El contenido de los tweets viene marcado por palabras clave (Cleary; Horsfall; Hayter, 2014; Silverman, 2016) que identifican la intención y la finalidad de un mensaje falso que se proyecta desde la TV y se reproduce sin control en Twitter. Los resultados constatan la presencia y reiteración de todas las categorías de falacias en los tweets en cualquiera de los temas difundidos. Los líderes, apoyados en los medios que facilita la Twitter, construyen una estrategia de discurso mediante el lenguaje de la espectacularización,

Las nuevas narrativas digitales agudizan las emociones, los conflictos y los escándalos, señas propias del debate televisado con efectos que hasta ahora no se han podido predecir

(Burkhardt, 2017). La conexión de temas, estrategias y usos del lenguaje, con independencia del tipo de audiencia al que se dirigen, es una marca de identidad de los líderes, que refuerza la posición de los partidos y la línea de sus programas.

La conclusión global que integra todas las unidades de estudio define un modelo de debate político determinado por la selección de los contenidos, las estrategias de juego y el discurso de la espectacularización. Se trata de identificadores de las multipantallas, que en las redes sociales multiplican las posibilidades de influencia del líder, a través de tácticas que favorecen la falacia, la confusión y la desinformación.

En este punto, podrían abrirse nuevos escenarios que amplíen el registro de teorías de la recepción (Bruun, 2016) y la audiencia social (D’Heer; Verdegem, 2015) o sobre los efectos de las fake news (Rodríguez-Ferrándiz, 2019) y los procesos de fact ckecking mediático (Vázquez Herrero; Vizoso; López-García, 2019) aplicados al entorno televisivo y digital del debate electoral.

\section{Notas}

1. Se hace referencia a cuota de pantalla y número total de espectadores que siguieron los debates desde cualquiera de las cadenas de TV que los ofrecieron en simulcast. La primera cita fue emitida por La 1, Canal 24 horas y las autonómicas IB3, Castilla-La Mancha Media, Canal Extremadura, Trece, CMM, Telemadrid, Canal Sur, Aragón TV y TPA 2, mientras que la segunda se focalizó en Antena 3 y La Sexta.

https://www.barloventocomunicacion.es/informes-barlovento/debate-electoral-22-abril-2019 
2. Informes de audiencias sobre los debates electorales previos a las elecciones del 28 de abril en España. https://www.barloventocomunicacion.es/wp-content/uploads/2019/04/NOTA-DE-PRENSA-DEBATE-22.04.19.pdf https://www.barloventocomunicacion.es/wp-content/uploads/2019/04/NOTA-DE-PRENSA-DEBATE-23.04.19-3.pdf

3. Información de sobre verificación en directo de fake news en los debates de RTVE y Atresmedia, 2019: https://www.newtral.es/el-fact-checking-de-newtral-en-el-debate-de-rtve/20190423 https://www.newtral.es/factchecking-en-directo-de-newtral-durante-el-debate-del-23a-en-atresmedia/2019

\section{Referencias}

Aalberg, Toril; De-Vreese, Claes H.; Strömbäck, Jesper (2017). "Strategy and game framing". In: De-Vreese, Claes H.; Esser, Frank; Hopmann, David N. (eds.). Comparing political journalism. London: Routledge, pp. 33-49. ISBN: 9781 138655850

Allcott, Hunt; Gentzkow, Matthew (2017). "Social media and fake news in the 2016 election". Journal of economic perspectives, v. 31, n. 2, pp. 211-236. https://doi.org/10.1257/jep.31.2.211

Anstead, Nick (2016). "A different beast? Televised election debates in parliamentary democracies". The international journal of press/politics, v. 21, n. 4, pp. 508-526. https://doi.org/10.1177/1940161216649953

Aragón, Pablo; Kappler, Karolin-Eva; Kaltenbrunner, Andreas; Laniado, David; Volkovich, Yana (2013). “Communication dynamics in Twitter during political campaigns: The case of the 2011 Spanish national election". Policy \& internet, v. 5, n. 2, pp. 183-206.

https://doi.org/10.1002/1944-2866.POI327

Arrese, Ángel (2016). "Política post-factual y sociedad post-mediática”. Nuevas tendencias, n. 97, pp. 8-14. http://hdl.handle.net/10171/44855

Aruguete, Natalia (2017). "The agenda setting hypothesis in the new media environment". Comunicación y sociedad, n. 28, pp. 35-58.

https://dialnet.unirioja.es/servlet/articulo?codigo=5774166

Baker, Paul (2006). Using corpora in discourse analysis. London: Continuum. ISBN: 9780826477255

Barlovento (2019a). Informe de audiencia. Debate electoral. 22 abril 2019. Barlovento Comunicación. https://www.barloventocomunicacion.es/wp-content/uploads/2019/04/NOTA-DE-PRENSA-DEBATE-22.04.19.pdf

Barlovento (2019b). Informe de audiencia. Debate electoral 23 abril 2019. Barlovento Comunicación. https://www.barloventocomunicacion.es/wp-content/uploads/2019/04/NOTA-DE-PRENSA-DEBATE-23.04.19-3.pdf

Barlovento (2019c). Informe sobre los debates electorales en televisión. 1993-2016. Barlovento Comunicación. https://www.barloventocomunicacion.es/wp-content/uploads/2019/04/DEBATES-ELECTORALES.pdf

Baym, Geoffrey D. (2010). From Cronkite to Colbert: The evolution of broadcast news. Boulder: Paradigm. ISBN: 9780 199945849

Beckett, Charlie; Deuze, Mark (2016). "On the role of emotion in the future of journalism". Social media + society, v. 2 , n. 3. https://doi.org/10.1177/2056305116662395

Benoit, William L.; Hansen, Glen J. (2004). "Presidential debate watching, issue knowledge, character evaluation, and vote choice". Human communication research, v. 30, n. 1, pp. 121-144.

https://doi.org/10.1111/j.1468-2958.2004.tb00727.x

Benoit, William L.; Hansen, Glen J.; Verser, Rebecca M. (2003). “A meta-analysis of the effects of viewing U.S. presidential debates". Communication monographs, v. 70, n. 4, pp. 335-350.

https://doi.org/10.1080/0363775032000179133

Berrocal-Gonzalo, Salomé (2003). “La personalización en la política”. En: Berrocal-Gonzalo, Salomé (coord.). Comunicación política en televisión y nuevos medios. Barcelona: Ariel, pp. 55-79. ISBN: 9788434412965

Boczkowski, Pablo J. (2016). "Las noticias falsas y el futuro del periodismo. La posverdad". Anfibia. http://revistaanfibia.com/ensayo/la-postverdad

Bruun, Hanne (2016). "The prism of change: 'Continuity' in public service television in the digital era”. Nordicom review, v. 37, n. 2 , pp. 33-49.

https://doi.org/10.1515/nor-2016-0016

Burkhardt, Joanna M. (2017). “Combatting fake news in the digital age”. Library technology reports, v. 53 , n. 8. https://www.journals.ala.org/index.php/Itr/issue/viewFile/662/423 
Caldevilla-Domínguez, David; Rodríguez-Terceño, José; Barrientos-Báez, Almudena (2019): “El malestar social a través de las nuevas tecnologías: Twitter como herramienta política". Revista latina de comunicación social, n. 74, pp. 12641290.

http://www.revistalatinacs.org/074paper/1383/66es.html

Campos-Domínguez, Eva (2017). "Twitter y la comunicación política". El profesional de la información, v. 26, n. 5, pp. 785-793.

https://doi.org/10.3145/epi.2017.sep.01

Campus, Donatella (2010). "Mediatization and personalization of politics in Italy and France: The cases of Berlusconi and Sarkozy". International journal of press/politics, v. 15, n. 2, pp. 219-235.

https://goo.gl/1AkC5B

https://doi.org/10.1177/1940161209358762

Caprara, Gian-Vittorio (2007). "The personalization of modern politics". European review, v. 15, n. 2, pp. $151-164$. https://doi.org/10.1017/S1062798707000178

Carrera-Boleas, Valentín (2015). "La red de confianza de los debates electorales y la mente de los candidatos". Marco. Revista de marketing y comunicación política, v. 1, p. 39-61.

https://revistas.usc.gal/index.php/marco/article/view/2767

Cartwright, Eduard; Stepanova, Anna; Xue, Lian (2019). "Impulse balance and framing effects in threshold public good games". Journal of public economic theory, v. 21, n. 5, pp. 903-922.

https://doi.org/10.1111/jpet.12359

Casero-Ripollés, Andreu; Ortells-Badenes, Sara; Rosique-Cedillo, Gloria (2014). “La espectacularización de la política. Consecuencias democráticas de la disolución de las fronteras entre información, entretenimiento y privacidad en la era digital". Telos: Cuadernos de comunicación e innovación, n. 99, pp. 45-54.

http://repositori.uji.es/xmlui/handle/10234/127530

Cha, Meeyoung; Haddadi, Hamed; Benevenuto, Fabrício; Gummadi, Krishna P. (2010). “Measuring user influence in Twitter: The million follower fallacy". In: Proceedings of International AAAl conference on weblogs and social media (ICWSM).

http://twitter.mpi-sws.org/icwsm2010_fallacy.pdf

Cleary, Michelle; Horsfall, Jan; Hayter, Mark (2014). “Data collection and sampling in qualitative research: does size matter?". Journal of advanced nursing, v. 70, n. 3, pp. 473-475.

https://doi.org/10.1111/jan.12163

Dader, José-Luis; Campos-Domínguez, Eva (coords.) (2017). La búsqueda digital del voto. Cibercampañas electorales en España 2015-16. Valencia: Tirant lo Blanch. ISBN: 9788491691853

D’Heer, Evelien; Verdegem, Pieter (2015). "What social media data mean for audience studies: a multidimensional investigation of Twitter use during a current affairs TV programme". Information, communication \& society, v. 18, n. 2, pp. 221-234.

https://doi.org/10.1080/1369118X.2014.952318

Enli, Gunn (2017). "Twitter as arena for the authentic outsider: Exploring the social media campaigns of Trump and Clinton in the 2016 US presidential election". European journal of communication, v. 32, n. 1, pp. 50-61.

https://doi.org/10.1177/0267323116682802

Flowerdew, John; Richardson, John E. (2017) The Routledge handbook of critical discourse studies. Taylor \& Francis. ISBN: 9781138826403

Freelon, Deen; Karpf, David (2015). “Of big birds and bayonets: hybrid Twitter interactivity in the 2012 presidential debates". Information, communication and society, v. 18, n. 4, pp. 390-406.

https://doi.org/10.1080/1369118X.2014.952659

Fuchs, Christian (2014). Social media: A critical introduction. London: Sage. ISBN: 9781446257319

https://doi.org/10.4135/9781446270066

Gainous, Jason; Wagner, Kevin M. (2014). Tweeting to power. The social media revolution in American politics. Oxford, UK: Oxford University Press. ISBN: 9780199965090

Galindo-Arranz, Fermín (1998). El debate político actual. Santiago de Compostela: Andavira Editora. ISBN: 97884 84080190

Gallardo-Camacho, Jorge; Lavín, Eva; Fernández-García, Paula (2015). “Analysis of the most discussed television programs on Twitter and their relationship with the traditional audience in Spain". Palabra clave, v. 19, n. 1, p. 185-210. http://www.scielo.org.co/scielo.php?script=sci_arttext\&pid=S0122-82852016000100008 
Gallego-Reguera, María; Bernárdez-Rodal, Asunción (2017). “Influencia y repercusión mediática de los debates 'cara a cara' celebrados ante las elecciones generales de 2008 en España: José Luis Rodríguez Zapatero (PSOE) vs Mariano Rajoy (PP)". Vivat academia, n. 141, pp. 139-154.

https://doi.org/10.15178/va.2017.141.139-154

García-Marín, Javier; Calatrava, Adolfo; Luengo, Óscar G. (2018). “Debates electorales y conflicto. Un análisis con máquinas de soporte virtual (SVM) de la cobertura mediática de los debates en España desde 2008". El profesional de la información, v. 27, n. 3, pp. 624-632.

https://doi.org/10.3145/epi.2018.may.15

Giglietto, Fabio; Selva, Donatella (2014). "Second screen and participation: a content analysis on a full season dataset of tweets". Journal of communication, v. 64, n. 2, pp. 260-277.

https://doi.org/10.1111/jcom.12085

Graham, Todd; Broersma, Marcel; Hazelhoff, Karin; Van't-Haar, Guido (2013). “Between broadcasting political messages and interacting with voters: the use of Twitter during the 2010 UK general election campaign". Information, communication \& society, v. 16, n. 5, pp. 692-716.

https://goo.gl/kHS5ZR

https://doi.org/10.1080/1369118X.2013.785581

Graves, Lucas; Cherubini, Federica (2016). The rise of fact-checking sites in Europe. Reuters Institute Digital News Report. https://ora.ox.ac.uk/objects/uuid:d55ef650-e351-4526-b942-6c9e00129ad7

Holtz-Bacha, Christina (2003). “Comunicación política: entre la privatización y la espectacularización”. Diálogo político, v. 1, pp. 137-154.

Jamieson, Kathleen H.; Adasiewicz, Cristopher (2000). “What can voters learn from election debates”. In: Coleman, Stephen (ed.). Televised election debates. International perspectives. New York: MacMillan, pp. 25-42. ISBN: 9780333732632 https://doi.org/10.1057/9780230379602_2

Journell, Wayne (2017). "Fake news, alternative facts, and Trump: Teaching social studies in a post-truth era". Social studies journal, v. 37, n. 1, pp. 8-21.

http://www.uncg.edu/ awjourne/Journell2017ssj.pdf

Jungherr, Andreas (2016). "Twitter use in election campaigns: a systematic literature review". Journal of information technology \& politics, v. 13, n. 1, pp. 72-91.

https://doi.org/10.1080/19331681.2015.1132401

Krippendorff, Klaus (2004). Content analysis: an introduction to its methodology. Thousand Oaks: Sage. ISBN: 9780 761915454

Lewandowsky, Stephan; Ecker, Ullrich K. H.; Cook, John (2017). “Beyond misinformation: Understanding and coping with the 'post-truth' era". Journal of applied research in memory and cognition, v. 6, pp.353-369.

https://doi.org/10.1016/j.jarmac.2017.07.008

López-Borrull, Alexandre; Vives-Gràcia, Josep; Badell, Joan-Isidre (2018). "Fake news, ċamenaza u oportunidad para los profesionales de la información y la documentación?". El profesional de la información, v. 27, n. 6, pp. 1346-1356.

https://doi.org/10.3145/epi.2018.nov.17

López-García, Guillermo (2016). “'New' vs 'old' leaderships: the campaign of Spanish general elections 2015 on Twitter”. Communication and society, v. 29, n. 3, pp. 149-168.

https://doi.org/10.15581/003.29.3.149-168

López-García, Guillermo; Llorca-Abad, Germán; Valera-Ordaz, Lidia; Peris-Blanes, Àlvar (2018). "Los debates electorales, ¿el último reducto frente la mediatización? Un estudio de caso de las elecciones generales españolas de 2015 ". Palabra clave, v. 21, n. 3, pp. 772-797.

https://doi.org/10.5294/pacla.2018.21.3.6

López-López, Paulo-Carlos; Oñate, Pablo (2019). “De la videopolítica a la ciberpolítica: debate entre candidatos y televisiones en cinco elecciones presidenciales". El profesional de la información, v. 28, n. 5, e280512.

https://doi.org/10.3145/epi.2019.sep.12

López-Meri, Amparo (2016). "Twitter-retórica para captar votos en campaña electoral. El caso de las elecciones de Cataluña de 2015". Comunicación y hombre, n. 12, pp. 97-118.

https://comunicacionyhombre.com/article/twitter-retorica-captar-votos-campana-electoral-caso-las-elecciones-cataluna-2015

López-Meri, Amparo; Marcos-García, Silvia; Casero-Ripollés, Andreu (2017). "What do politicians do on Twitter? Functions and communication strategies in the Spanish electoral campaign of 2016". El profesional de la información, v. 26, n. 5, pp. 795-804.

https://doi.org/10.3145/epi.2017.sep.02 
Lorente-Cano, Mónica (2011). “'Social TV' en España: concepto, desarrollo e implicaciones”. Cuadernos de gestión de información, v. 1, pp. 55-64.

https://revistas.um.es/gesinfo/article/view/207531

Luengo, Óscar G. (2011). "Debates electorales en televisión: una aproximación preliminar a sus efectos inmediatos". Revista española de ciencia política, n. 25, pp. 81-96.

https://recyt.fecyt.es/index.php/recp/article/view/37516

Marín, Benjamín (2003). “Debates electorales por televisión”. En: Berrocal-Gonzalo, Salomé (coord.). Comunicación política en televisión y nuevos medios. Barcelona: Ariel. ISBN: 9788434412965.

Marzal-Felici, Javier; Casero-Ripollés, Andreu (2017). “Editorial. El fotoperiodismo en la era de la posverdad". AdComunica, n. 13, pp. 11-17.

http://www.adcomunicarevista.com/ojs/index.php/adcomunica/article/view/382/338

Mazaira-Castro, Andrés; Rúas-Araújo, José; Puentes-Rivera, Iván (2019). “Fact-checking en los debates electorales televisados de las elecciones generales de 2015 y 2016". Revista latina de comunicación social, n. 74, pp. 748-766. https://doi.org/10.4185/RLCS-2019-1355

McCombs, Malcom (2005). “A look at agenda-setting: past, present and future”. Journalism studies, v. 6, n. 4, pp. 543557.

https://doi.org/10.1080/14616700500250438

McNair, Brian (2018). Fake news: Falsehood, fabrication and fantasy in journalism. London: Routledge. ISBN: 9781 138306790

Mellado, Claudia; Hellmueller, Lea; Donsbach, Wolfgang (2017). Journalistic role performance: Concepts, contexts, and methods. New York: Routledge. ISBN: 9781315768854

https://bit.ly/2whOOTg

Meraz, Sharon (2011). "Using time series analysis to measure intermedia agenda-setting influence in traditional media and political blog networks". Journalism \& mass communication quarterly, v. 88, n. 1, pp. 176-194.

https://doi.org/10.1177/107769901108800110

Miranda-Bustamante, María-de-los-Ángeles; Fernández-Medina, Francisco (2015). "Hablándole a la televisión: análisis de las conexiones discursivas entre Twitter y tres programas de contenido político en televisión abierta". Comunicación y sociedad, n. 24, pp. 71-94.

https://dialnet.unirioja.es/servlet/articulo?codigo $=5301832$

Montoya, Peter; Vandehey, Tim (2009). The brand called you. Create a personal branding that wins attention and grows your business. London: McGraw-Hill. ISBN: 9780071597500

Naderi, Nona; Hirst, Graeme (2018). "Automated fact-checking of claims in argumentative parliamentary debate". In: Proceedings of the First workshop on fact extraction and verification (Fever). Brussels: Association for Computational Linguistics, pp. 60-65

https://www.aclweb.org/anthology/W18-5509

Neuendorf, Kimberly A. (2002). The content analysis guidebook. Thousand Oaks (CA): Sage Publications. ISBN: 9781 412979474

Nocetti, Oscar (1990). Falacias y medios de comunicación. El discurso como arma. Buenos Aires: Editorial Humanitas.

Padilla-Castillo, Graciella (2014). "La espectacularización del debate electoral: estudio del caso de Estados Unidos". Vivat academia, n. 128, pp. 107-123.

https://www.vivatacademia.net/index.php/vivat/article/view/587

Pérez-Curiel, Concha; García-Gordillo, Mar (2019). “Formato televisivo proyección en Twitter de las elecciones en Andalucía". En: Conde-Vázquez, Erica; Fontenla-Pedreira, Julia Rúas-Araújo, José (eds.). Debates electorales televisados: del antes al después. Cuadernos Artesanos de Comunicación, n. 154. La Laguna (Tenerife): Latina, pp. 259-285.

https://doi.org/10.4185/cac154

Pérez-Curiel, Concha; Limón-Naharro, Pilar (2019): “Influencers de la política. Estudio de la marca personal de Donald Trump en Twitter y efectos en medios y usuarios". Communication \& society, v. 32, n. 1, pp. 57-76.

https://dadun.unav.edu/handle/10171/57833

https://doi.org/10.15581/003.32.1.57-75

Pérez-Ortega, Andrés (2014). Marca personal para dummies. Barcelona. ISBN: 9788432903557

Potter, Deborah (2006). Handbook of independent journalism. Bureau of International Information Programs. https://archive.org/details/HandbookOfIndependentJournalism/mode/2up 
Rahat, Gideon; Sheafer, Tamir (2007). "The personalization(s) of politics: Israel, 1949-2003". Political communication, v. 24, n. 1, pp. 65-80.

https://doi.org/10.1080/10584600601128739

Rampersad, Hubert K. (2009). Authentic personal branding: a new blueprint for building and aligning a powerful leadership brand. San Bernardino, CA: IAP. ISBN: 9781607520993

Reinemann, Carsten; Wilke, Jürgen (2007). "It's the debates, stupid! How the introduction of televised debates changed the portrayal of chancellor candidates in the German press, 1949-2005". International journal of press/politics, v. 12, n. 4, pp. 92-111.

https://doi.org/10.1177/1081180X07307185

Rochlin, Nick (2017). “Fake news: belief in post-truth". Library hi tech, v. 35, n. 3, pp. 386-392. https://doi.org/10.1108/LHT-03-2017-0062

Rodríguez-Ferrándiz, Raúl (2019). "Posverdad y fake news en comunicación política: breve genealogía". El profesional de la información, v. 28, n. 3, e280314. https://doi.org/10.3145/epi.2019.may.14

Rúas-Araújo, José; Quintas-Froufe, Natalia (2020). "Televisión, audiencias y debates electorales: hacia la multipantalla”. El profesional de la información, v. 29, n. 2, e290201.

https://doi.org/10.3145/epi.2020.mar.01

Ruiz-del-Olmo, Francisco-Javier; Bustos-Díaz, Javier (2016). “Del tweet a la fotografía, la evolución de la comunicación política en Twitter hacia la imagen. El caso del debate del estado de la nación en España (2015)". Revista latina de comunicación social, n. 71, pp. 108-123.

https://doi.org/10.4185/RLCS-2016-1086

Sadiku, Matthew; Eze, Tochukwu; Musa, Sarhan (2018). "Fake news and missinformation". International journal of advances in scientific research and engineering (Ijasre), v. 4, n. 5, pp. 187-190.

https://www.ijasre.net/index.php/ijasre/article/view/1007

Said-Hung, Elías M.; Prati, Ronaldo, C.; Cancino-Borbón, Andrea (2017). "La orientación ideológica de los mensajes publicados en Twitter durante el 24M en España”. Palabra clave, v. 20, n. 1, pp. 213-238.

https://doi.org/10.5294/pacla.2017.20.1.10

Sampedro-Blanco, Víctor; Sánchez-Duarte, José-Manuel; Poletti, Mónica (2013). "Ciudadanía y tecnopolítica electoral. Ideales y límites burocráticos a la participación digital". Coherencia, v. 10, n. 18, pp. 105-136.

https://dialnet.unirioja.es/servlet/articulo?codigo $=5652578$

Silverman, David (2016). Qualitative research. Sage Publication Ltd. ISBN: 9781473916562

Soengas, Xosé (2009). "Los límites de la información en los debates pactados". Revista latina de comunicación social, n. 64, pp. 988-999.

https://doi.org/10.4185/RLCS-64-2009-875-988-999

Stromer-Galley, Jennifer (2014). Presidential campaigning in the internet age. Oxford University Press. ISBN: 9780 199731947

Sung-Tae, Kim; Young-hwan, Lu (2007). “New functions of Internet mediated agenda-setting: Korea”. Journalism review, v. 1, n. 2, pp. 3-29.

Thelwall, Mike; Cugelman, Brian (2017). "Monitoring Twitter strategies to discover resonating topics: The case of the UNDP”. El profesional de la información, v. 26, n. 4, pp. 649-661.

https://doi.org/10.3145/epi.2017.jul.09

Urmeneta, Miguel (2017). "Lecciones verdaderas tras las 'fake news'”. Aceprensa, 20 febrero.

http://www.aceprensa.com/articles/lecciones-verdaderas-tras-las-fake-news

Vaccari, Cristian; Chadwick, Andrew; O'Loughlin, Ben (2015). “Dual screening the political: media events, social media, and citizen engagement". Journal of communication, v. 65, n. 6, pp. 1041-1061.

https://doi.org/10.1111/jcom.12187

Van-Dijck, Teun A. (2015). "Critical discourse studies. A sociocognitive approach". Methods of critical discourse studies, v. 3, n. 1, pp. 63-74.

https://www.researchgate.net/publication/265620660_Critical_Discourse_Studies_A_Sociocognitive_Approach_1

Vázquez-Herrero, Jorge; Vizoso, Ángel; López-García, Xosé (2019). “Innovación tecnológica y comunicativa para combatir la desinformación: 135 experiencias para un cambio de rumbo”. El profesional de la información, v. 28, n. 3, e280301. https://doi.org/10.3145/epi.2019.may.01 
Verweij, Peter (2012). "Twitter links between politicians and journalists". Journalism practice, v. 6, n. 5-6, pp. 680-691. https://doi.org/10.1080/17512786.2012.667272

Vosoughi, Soroush; Roy, Deb; Aral, Sinan (2018). "The spread of true and false news online". Science, v. 359, n. 6380, pp. 1146-1151.

https://doi.org/10.1126/science.aap9559

Wallsten, Kevin (2007). "Agenda setting and the blogosphere: an analysis of the relationship between mainstream media and political blogs". Review of policy research, v. 24, n. 6, pp. 567-587.

https://doi.org/10.1111/j.1541-1338.2007.00300.x

Wintersieck, Amanda (2017). "Debating the truth: the impact of fact-checking during electoral debates". American politics research, v. 45, n. 2, pp. 304-331.

https://doi.org/10.1177/1532673X16686555

Wodak, Ruth; Meyer, Michael (2009). “Critical discourse analysis: history, agenda, theory and methodology. Methods of critical discourse analysis, n. 2, pp. 1-33.

https://www.corwin.com/sites/default/files/upm-binaries/24615_01_Wodak_Ch_01.pdf

Wohn, Yvette; Na, Eun-Kyung (2016). "Tweeting about TV: Sharing television viewing experiences via social media message streams". First Monday, n. 16.

https://doi.org/10.5210/fm.v16i3.3368

Yawn, Mike; Beatty, Bob (2000). "Debate-induced opinion change. What matters?". American politics quarterly, v. 28, n. 2, pp. 270-285.

https://doi.org/10.1177/1532673X00028002007

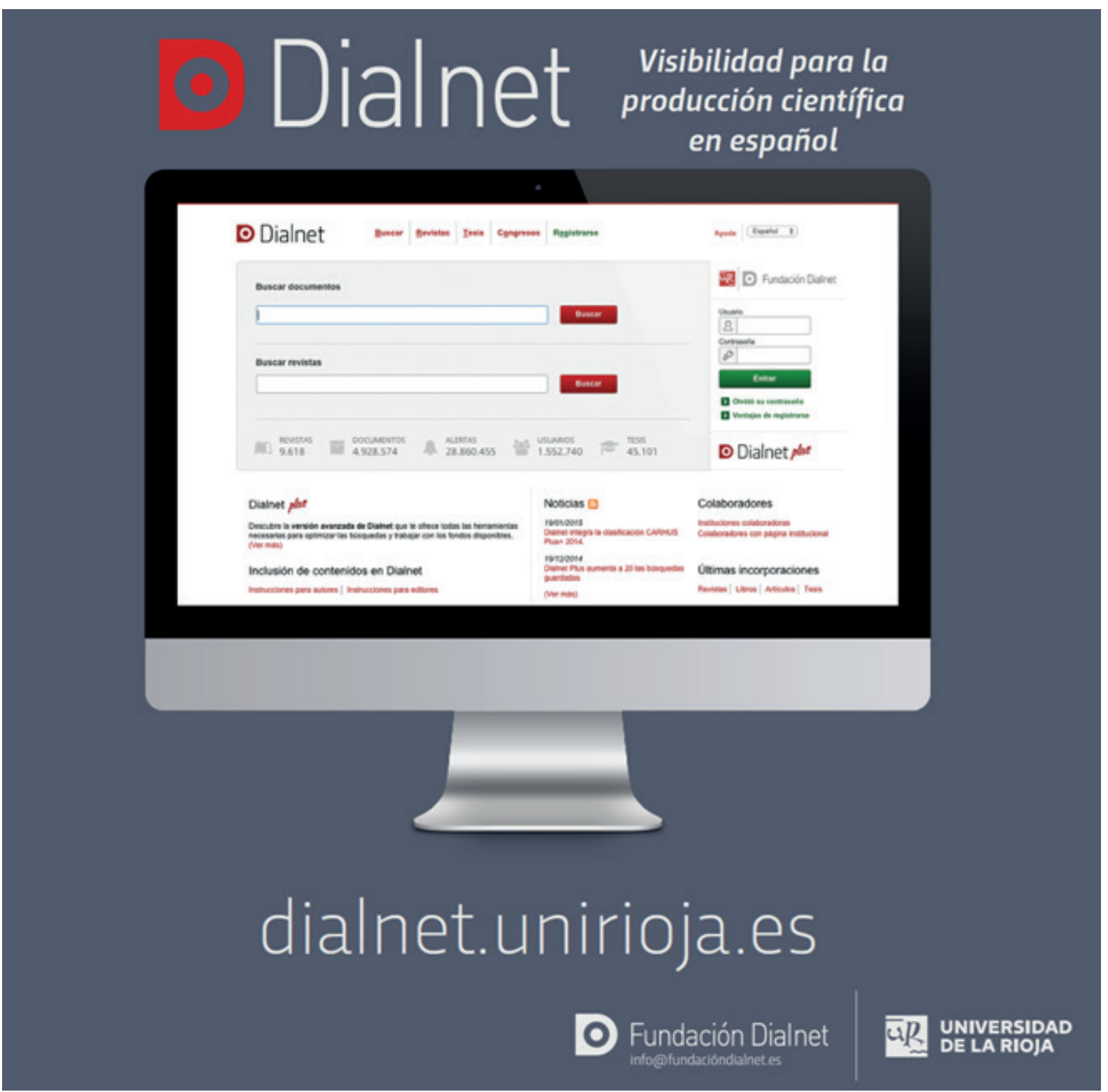

